\title{
Assembly and comparative analysis of complete mitochondrial genome sequence of an economic plant Salix suchowensis
}

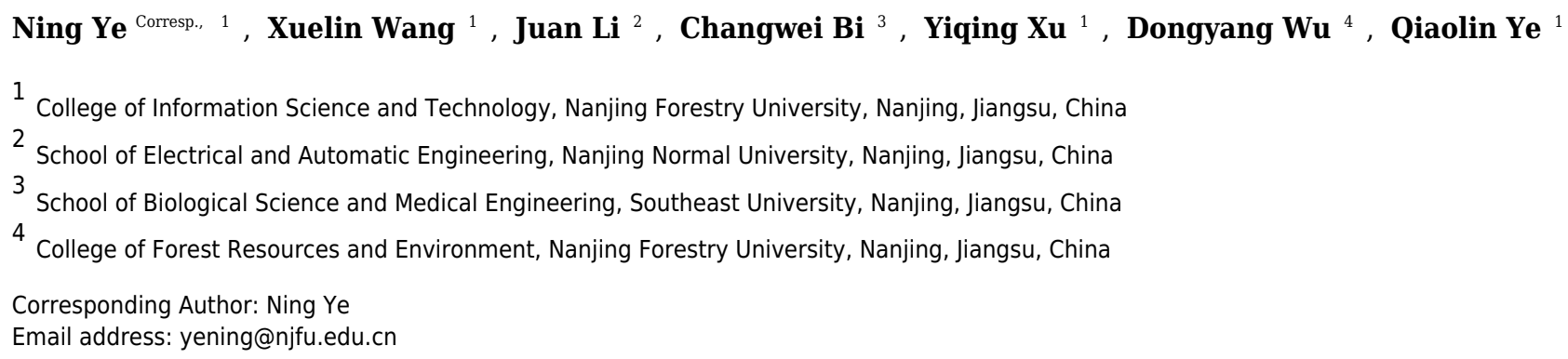

Willow is a widely used dioecious woody plant of Salicaceae family in China. Due to their high biomass yields, willows are promising sources for bioenergy crops. In this study, we assembled the complete mitochondrial $(\mathrm{mt})$ genome sequence of $S$. suchowensis with the length of 644,437 bp using Roche-454 GS FLX Titanium sequencing technologies. Base composition of the S. suchowensis $\mathrm{mt}$ genome is A $(27.43 \%), \mathrm{T}(27.59 \%), \mathrm{C}(22.34 \%)$, and G $(22.64 \%)$, which shows a prevalent GC content with that of other angiosperms. This long circular mt genome encodes 58 unique genes (32 protein-coding genes, 23 tRNA genes and 3 rRNA genes), and 9 of the 32 protein-coding genes contain 17 introns. Through the phylogenetic analysis of 35 species based on 23 protein-coding genes, it is supported that Salix as a sister to Populus. With the detailed phylogenetic information and the identification of phylogenetic position, some ribosomal protein genes and succinate dehydrogenase genes are found usually lost during evolution. As a native shrub willow species, this worthwhile research of $S$. suchowensis mt genome will provide more desirable information for better understanding the genomic breeding and missing pieces of sex determination evolution in the future. 


\section{Assembly and Comparative Analysis of Complete mitochondrial}

\section{2 genome sequence of an Economic Plant Salix suchowensis}

3 Ning $\mathrm{Ye}^{\mathrm{i}^{*}}$, Xuelin Wang ${ }^{1}$, Juan $\mathrm{Li}^{2}$, Changwei $\mathrm{Bi}^{3}$, Yiqing $\mathrm{Xu}^{1}$, Dongyang $\mathrm{Wu}^{4}$, 4 Qiaolin $\mathrm{Ye}^{1}$

5 1. College of Information Science and Technology, Nanjing Forestry University,

6 Nanjing, Jiangsu, China

2. School of Electrical and Automation Engineering, Nanjing Normal University, Nanjing, Jiangsu, China

3. School of Biological Science and Medical Engineering, Southeast University, Nanjing, Jiangsu, China

7 4. College of Forest Resources and Environment, Nanjing Forestry University,

8 Nanjing, Jiangsu, China

9

$10 *$ Corresponding author

11

12 Ning Ye, yening@njfu.edu.cn

13 Xuelin Wang, xlin.wang@qq.com

14 Juan Li, lijuannnu@163.com

15 Changwei Bi, bichwei@163.com

16 Yiqing Xu, yiqingxu@njfu.edu.cn

17 Dongyang Wu, wudongyang@njfu.edu.cn

18 Qiaolin Ye, yeqiaolincom@163.com

19 


\section{Manuscript to be reviewed}

\section{Abstract}

21 Willow is a widely used dioecious woody plant of Salicaceae family in China. Due to

22 their high biomass yields, willows are promising sources for bioenergy crops. In this

23 study, we assembled the complete mitochondrial ( $\mathrm{mt}$ ) genome sequence of Salix

24 suchowensis with the length of 644,437 bp using Roche-454 GS FLX Titanium

25 sequencing technologies. Base composition of the $S$. suchowensis $\mathrm{mt}$ genome is A

26 (27.43\%), T (27.59\%), C (22.34\%), and G (22.64\%), which shows a prevalent GC

27 content with that of other angiosperms. This long circular mt genome encodes 58

28 unique genes (32 protein-coding genes, 23 tRNA genes and 3 rRNA genes), and 9 of

29 the 32 protein-coding genes contain 17 introns. Through the phylogenetic analysis of

3035 species based on 23 protein-coding genes, it is supported that Salix as a sister to

31 Populus. With the detailed phylogenetic information and the identification of

32 phylogenetic position, some ribosomal protein genes and succinate dehydrogenase

33 genes are found usually lost during evolution. As a native shrub willow species, this

34 worthwhile research of $S$. suchowensis $\mathrm{mt}$ genome will provide more desirable

35 information for better understanding the genomic breeding and missing pieces of sex

36 determination evolution in the future. 


\section{Manuscript to be reviewed}

\section{Introduction}

Salicaceae, a family of dioecious catkin-bearing woody plants mainly including willows (Salix), poplars (Populus) and Chosenia, are well known for their worldwide diverse uses (Dai et al. 2014). Most willow species with small, short or exceptional stems flower early during their lives and thus differ from poplars in their living habits and histories (Stettler et al. 1996). As a widespread bush willow species of Salicaceae family in China, S. suchowensis could reach sexual maturity in one year to propagate.

Mitochondria are organelles, whose main function is to convert the energy from biomass energy into chemical energy in living cells. The origin of plastids and mitochondria are through the endosymbiotic acquisition of formerly free-living bacteria, which can explain the presence of own genomes (Greiner \& Bock 2013; Keeling 2010; Sagan 1967). After more than a billion years of concerted subsequent evolution to optimize the compartmentalized genetic material expression, the three genomes of plant cells (nucleus, plastid and mitochondrion) have undergone dramatic structural changes (Greiner \& Bock 2013). For most seed plants, nuclear hereditary information is inherited biparentally, while both chloroplasts (cp) and mitochondria are derived from maternal genes (Birky 1995). The mt genome plays a significant role in plant productivity and development (Yasunari et al. 2005). Previous studies showed that plant mt genomes with abundant genes were large and complex compared to other non-plant eukaryotes ( $\mathrm{Li}$ et al. 2009b; Yang et al. 2011). During the evolution of plant mt genomes, land plants probably have obtained some new mechanisms to assist more frequent gene exchanges between $\mathrm{mt}$ and nuclear genomes, as well as $\mathrm{mt}$ and $\mathrm{cp}$ genomes (Fujii et al. 2010). It is also suggested that seed plant mt genomes are distinct for their very low mutation rate generally (Palmer \& Herbon 1988; Wolfe et al. 1987), dynamic structure (Lonsdale et al. 1988), repeatedly uptake of foreign DNA by intracellular and horizontal gene transfer (Richardson \& Palmer 2007; Stern \& Lonsdale 1982), relatively high incidence of trans-splicing of coding sequences and RNA editing (Knoop 2004; Schuster et al. 1990), and their extremely large and highly variable sizes (Hsu \& Mullin 1989; Ward et al. 1981).

An increasing number of organelle genomes have been completed in the past several years. Until now, there are 255 complete mt genomes having been deposited in GenBank Organelle Genome Resources. The plant mt genomes vary considerably in length (varying from 200 to $700 \mathrm{~kb}$ mostly), gene order and gene content (Richardson et al. 2013). The largest published land plants mt genome of Silene conica is $11.3 \mathrm{Mb}$ in length (Sloan et al. 2012) and the smallest of known land plants $\mathrm{mt}$ genome is about $66 \mathrm{~kb}$ (Viscum scurruloideum) in length (Skippington et al. 2015). The gene content of land plants also varies considerably, mainly ranging from 32 to 67 genes, and some genes like NADH dehydrogenase subunit are encoded in discontinuous fragments that require trans-splicing event (Hsu \& Mullin 1989; Ward et al. 1981). With the emergence of next-generation sequences, new approaches for high-throughput, timesaving and low-cost genome sequencing will be applied 
79 gradually. Populus trichocarpa was a well-studied model tree in many other different

80 types of research and it was the first sequenced wood plant in the family of Salicaceae

81 (Tuskan et al. 2006). In this study, we determined the complete mt genome sequence

82 of $S$. suchowensis. The complete cp genome of this specie has already been reported

83 (Wu 2014), but its $\mathrm{mt}$ genome has not been determined. We also analyze the genomic

84 and structural features of $S$. suchowensis $\mathrm{mt}$ genome and make a comparison with

85 other angiosperms and gymnosperms at the same time, which will provide

86 information for the better understanding of $\mathrm{mt}$ genome evolution in land plants.

87 Further and more importantly, this study could bring more desirable information for

88 better understanding the genetic transformation, genomic breeding (Wu 2014) and

89 missing pieces of sex determination evolution in the future (Kersten et al. 2016).

\section{$90 \quad$ Materials and Methods}

\section{Genome Sequencing Preparation}

92 To construct, amplify and sequence the original genome sequencing libraries, we used

93 Roche/454 and Illumina/HiSeq-2000 sequencing technologies according to the

94 manufacture's kits and protocols. The $S$. suchowensis $\mathrm{mt}$ genome sequencing was

95 conducted with a combined approach using Roche/454 and Illumina/HiSeq-2000

96 sequencing technologies at Nanjing Forestry University following the manufacturer's

97 protocols (Dai et al. 2014; Liu et al. 2013).

98

\section{Genome Assembly and Annotation}

To generate a scaffold-level and gap-free mitochondrial genome of S. suchowensis, we used the 454 GS FLX Titanium platform (454 Life Sciences) in this research. As shown in supplementary Table S1, we got 1,240,387 high-quality reads with a total length of $702,204,081 \mathrm{bp}$. The average read length is $567 \mathrm{bp}$, and the longest read length is $1,201 \mathrm{bp}$. Since the original sequence reads were a mixture of DNA with the nucleus and other organelles like chloroplast, basing on 255 known reference $\mathrm{mt}$ genomes download from NCBI, we used BLASTN to isolate mitochondrial reads from the total reads (Buhler et al. 2007). Newbler 3.0 (454-Roche) with default parameters was used to assemble the $S$. suchowensis $\mathrm{mt}$ genome sequences. After this process, we obtained 83,984 contigs, and the longest contig length is 349,730 bp. Contigs with long length and high reads depth were separated with shorter ones (Zhang et al. 2011). We filtered contigs with read depth between $15 x$ to $50 x$ out, which may contain essential mitochondrial genes. According to the manual of the assembly software Newbler (Zhang et al. 2011), contigs are constructed and almost no overlaps among these connected contigs. Therefore, we used Perl scripts and Newbler 3.0 


\section{Manuscript to be reviewed}

114 (454-Roche) generated file "454AllContigGraph.txt" to determine the contigs

115 connections. According to read depths of the contigs, false links and some wrong forks

116 were removed manually in the meanwhile, and we finally obtained 13 contigs to

117 construct the draft connection graph for assembling the mt genome. As shown in

118 supplementary Table S2 and Fig. S1, three contigs (Contig30222, Contig34550 and

119 Contig55858) resemble cp-derived sequences with their high coverages. However,

120 with the connection in file '454ContigGraph.txt', these three contigs are essential for

121 assembling the complete mt genome, suggesting that these three contigs may be

122 derived from the $S$. suchowensis cp genome. Additionally, 3 of the 13 selected contigs

123 (Contig00022, Contig00027 and Contig55858) were assembled into the complete $\mathrm{mt}$

124 genome twice, indicating that these three contigs are repeat sequences in $S$.

125 suchowensis mt genomes. After that, we used the method described by Ji et al. (Ji et al.

126 2013) to fill the gaps of contigs up : first, we mapped mitochondrial reads onto both

127 ends (3-60 bp) of the assembled contigs and then extended the contigs by joining the

128 reads, which were partly overlapped (Identity $\geq 95 \%$; e-value $\leq 1 \mathrm{e}-30$ ) with the contigs.

129 In order to get a more accurate genome, we used 64 Illumina (Illumina Genome

130 Analyzer II) runs (Accession: SRX1561932, $51.2 \mathrm{~Gb}$ ) generated by a standard Solexa

131 protocol to validate the genome assembly. Using BWA (Li \& Durbin 2009)and

132 SAMtools ( $\mathrm{Li}$ et al. 2009a), we mapped the Illumina sequencing data onto the draft $\mathrm{mt}$

133 genome assembled by Roche 454 sequencing date, and then we filtered the mapped

134 reads with local Perl scripts. After reassembling these mapped reads with Newbler

135 software, a total of 214 contigs (longest length: 16,445 bp, average length: 2,271 bp,

136 N50: 3,254 bp) with total length 486,008 bp were generated. Next, we remapped the

137214 contigs onto the draft $\mathrm{mt}$ genome in MacVector, and corrected 168 sequencing

138 mistakes generated by 454 GS FLX Titanium platform (especially in A/T enriched

139 regions). Finally, the complete mt genome sequence of $S$. suchowensis was finished.

140 The Web-based tool Public MITOFY Analysis was used to identify genes (Alverson

141 et al. 2010), accompanying with synonymous and none-synonymous SNPs. We also

142 revised the start and stop codons of genes by learning similar genes, which has been

143 manually checked by MITOFY firstly from other mt genomes sequenced. All transfer

144 RNA genes were confirmed by using tRNAscan-SE with default settings (Schattner et

145 al. 2005). The circular mt genome map was drawn through the OGDRAW online

146 program (Lohse et al. 2007). The final $\mathrm{mt}$ genome of $S$. suchowensis has been

147 deposited to GenBank (Accession number: NC 029317.1)

148 Analysis of Repeat Structure and Sequence

149 Simple sequence repeats (SSRs) of the S. suchowensis $\mathrm{mt}$ genome were discovered 150 using Perl script MISA (http://pgrc.ipkgatersleben.de/misa/) (Thiel et al. 2003), with

151 the size of one to six nucleotides and thresholds of eight, four, four, three, three, and

152 three, separately. Tandem repeats were analyzed with the aid of Tandem Repeats

153 Finder Program v4.04 (Benson 1999) using default parameters. Additionally,

PeerJ reviewing PDF | (2017:01:15495:2:0:NEW 27 Feb 2017) 


\section{Manuscript to be reviewed}

154 AB-blast was utilized to identify and locate disperse repeats with the following

155 parameters: $\mathrm{M}=1, \mathrm{~N}=-3, \mathrm{Q}=3, \mathrm{R}=3$, kap, span, $\mathrm{B}=1 \times 10^{9}$ and $\mathrm{W}=7$, which have

156 been proved effectively in other $\mathrm{mt}$ genomes (Alverson et al. 2010; Alverson et al.

157 2011; Bi et al. 2016). The BLAST hits with e-value $\leq 1$ and identity $\geq 80 \%$ were

158 considered as disperse repeats. All of the repeats sequence identified with the

159 above-mentioned programs were manually checked to filter excessive results.

160 Analysis of RNA editing and Substitution Rate

161 The online program Predictive RNA Editor for Plants (PREP) suite

162 (http://prep.unl.edu/) (Mower 2009) was adopted to identify the possible RNA editing

163 sites in the protein-coding genes of S. suchowensis $\mathrm{mt}$ genome. For the sake of an

164 accurate prediction, the cutoff value was set as 0.2 . The protein-coding genes from

165 other plant $\mathrm{mt}$ genomes were utilized as references for revealing the RNA editing sites

166 in the S. suchowensis $\mathrm{mt}$ genome.

167 In order to analyze the synonymous (Ks) and nonsynonymous $(\mathrm{Ka})$ substitution

168 rates of the protein-coding genes in S. suchowensis and other higher plant mt genomes,

169 Gossypium raimondii was selected as reference. Protein sequences of the

170 corresponding protein-coding genes in S. suchowensis and G. raimondii mt genomes

171 were extracted and then aligned separately using ClustalW (Thompson et al. 2002).

172 The Ks and Ka substitution rates of each protein-coding gene were finally estimated

173 in DnaSP v5.10 with default settings (Librado \& Rozas 2009).

\section{DNA Transfer from Chloroplast to Mitochondrion}

175

176

177

178

179

180

181

182

183

184

185

186

187
The migration of DNA segments between $\mathrm{cp}$ and $\mathrm{mt}$ genomes has been identified unidirectional from $\mathrm{cp}$ to $\mathrm{mt}$ genomes in most higher plants (Chang et al. 2013), only a few examples of DNA transfer from $\mathrm{mt}$ to $\mathrm{cp}$ genome (Smith 2014). The cp genome of S. suchowensis (NC_026462) was downloaded from the NCBI Organelle Genome Resources database. DNA segments transferred from $S$. suchowensis $\mathrm{cp}$ to $\mathrm{mt}$ genomes were identified by NCBI-BLASTn with stringent parameters: -evalue 1e-6, -word_size 9, -gapopen 5, -gapextend 2, -reward 2, -penalty -3, and -dust no. In order to identify cp-derived sequences and detect conserved mt sequences, the $S$. suchowensis $\mathrm{cp}$ genome was searched against a database composed of 25 representative seed plant cp genomes using NCBI-BLASTn with the same stringent parameters. Additionally, protein-coding and tRNA genes transferred from $\mathrm{cp}$ to $\mathrm{mt}$ genomes were also identified by NCBI-BLASTn, and the results with identity $\geqslant 90 \%$, e-value $\leqslant 1$ e-10 and coverage $\geqslant 90 \%$ were selected as candidates. 


\section{Manuscript to be reviewed}

188

189

190

191

192

193

194

195

196

197

198

199

200

201

202

203

204

205

206

207

208

209

210

211

212

\section{3}

214

215

216

217

218

219

220

221

222

223

\section{Phylogenetic Analysis}

In order to acquire the phylogenetic position of S. suchowensis, 35 plant mt genomes (Ajuga reptans, Asclepias syriaca, Arabidopsis thaliana, Batis maritima, Brassica napus, Butomus umbellatus, Beta vulgaris, Capsicum annuum, Citrullus lanatus, Carica papaya, Cucurbita pepo, Cucumis sativus, Cycas taitungensis, Daucus carota, Ginkgo biloba, Glycine max, Gossypium hirsutum, Gossypium raimondii, Lotus japonicas, Malus domestica, Marchantia pinnata, Medicago truncatula, Nicotiana tabacum, Oryza sativa, Phoenix dactylifera, Populus tremula, Raphanus sativus, Rhazya stricta, Sorghum bicolor, Salvia miltiorrhiza, Salix suchowensis, Tripsacum dactyloides, Vigna angularis, Vitis vinifera and Zea mays) were downloaded from the NCBI Organelle Genome Resources database (http://www.ncbi.nlm.nih.gov/genome/organelle/). Among these species, not only the complete $\mathrm{mt}$ genome sequences of these species for analysis were available in NCBI, but also, they were placed clearly in taxonomy and were widely used. Phylogenetic analyses were performed on 23 conserved protein-coding genes (atp1, atp4, atp6, atp8, atp9, ccmB, ccmC, ccmFc, ccmFn, cob, cox1, cox2, cox3, matR, nad1, nad2, nad3, nad4, nad4L, nad5, nad6, nad7 and nad9), which were extracted from these 35 plant mt genomes by local Perl scripts. These conserved genes were then aligned using Muscle (Edgar 2004) implemented in MEGA 6.0 (Tamura et al. 2013), and the alignment was modified manually to eliminate gaps and missing data. Finally, a Neighbor-joining (NJ) tree was constructed in MEGA 6.0 with the Poisson model, and the rates among sites were set as Uniform rates. The bootstrap consensus tree was inferred from 1000 replications. C. taitungensis and G. biloba were designated as the outgroup.

\section{Results and Discussion}

\section{Genomic Features of the $S$. suchowensis mt genome}

The complete mitochondrial genome of $S$. suchowensis is 644,437 bp in length (GenBank accession number: NC_029317.1) with a typical circular structure of land plant genomes. The overall base composition of the entire genome is as follows: A: $27.43 \%$, T: $27.59 \%$, G: $22.64 \%$, C: $22.34 \%$, and the GC content is $44.98 \%$. The positions of all the genes identified in the S. suchowensis mt genome and functional categorization of these genes are presented in Fig. 1. A total of 58 unique genes were identified in the $S$. suchowensis $\mathrm{mt}$ genome, including 32 protein-coding genes, 23 tRNA genes and 3 rRNA genes (Table 1). Interestingly, the mt genome contains two copies of $r p s 7$ gene.

As shown in Table 1, most of the protein-coding genes use ATG as their start codon, 


\section{Manuscript to be reviewed}

224 except $r p l 16$ and $m t t B$, which have undetermined start codons. Two genes ( $r p l 16$ and

225

226

227

228

229

230

231

232

233

234

235

236

237

238

239

240

241

242

243

244

245 $m t t B$ ) have been reported to have undetermined start codons in many higher plant $m t$ genomes (Bi et al. 2016; Handa 2003; Oda et al. 1992). The usages of the stop codons in S. suchowensis mt protein-coding genes are TAA (16 genes; atp6, coxl, cox 2, nad1, nad2, nad3, nad4L, nad5, nad9, rpl2, rpl10, rpl16, rps3, rps4, rps 7 and sdh4), TAG (8 genes; atp 4, atp8, atp9, ccmFc, mttB, matR, nad6 and nad7) and TGA (8 genes; atp1, $c c m B, c c m C, c c m F n, c o b, c o x 3$, nad4 and rps 1), suggesting that there is no $\mathrm{C}$ to $\mathrm{U}$ RNA editing event happened in the stop codons. Furthermore, with the purpose of exhibiting the details of the $S$. suchowensis mt genome better, a GBrowse (Fig. S2) was built at http://bio.njfu.edu.cn/gb2/gbrowse/Salix_Suchowensis_mt/.

As shown in Table 2, protein-coding genes and cis-introns regions account for $4.68 \%$ and $4.21 \%$ (27,122 bp) of the whole $S$. suchowensis genome sequence, respectively, while the proportions of rRNA and tRNA regions only represent $0.83 \%$ and $0.27 \%$. The remaining regions are non-coding sequences, including introns, intergenic spacers and may be pseudogenes. Specifically, the total length of all the 33 protein-coding genes is 30,141 bp and these genes comprise 10,047 codons. Among these codons, $11.4 \%(1,141)$ of them encode Leucine, and 1.6\% (165) of which encode Tryptophan, which are the most and least common amino acids, independently. What's more, with the comparison of genome features in six higher plant mt genomes (Table 2), we found that the coding genes were conserved but the proportions of coding regions were extremely different from each other probably due to their different sizes of $\mathrm{mt}$ genomes.

\section{Identification of repeat sequences in the $S$. suchowensis $\mathrm{mt}$}

\section{genome}

As described by $\mathrm{Bi}$ et al. (Bi et al. 2016), repeat sequences are composed of simple sequence repeats (SSRs), tandem repeats, short repeats and large repeats. The simple sequence repeats are a group of tandem repeated sequences with the size of one to six nucleotide repeat units (Chen et al. 2006). A total of 430 SSRs were discovered in $S$. suchowensis mt genome, including 181 (42.09\%) monomers, 168 (39.07\%) dimers, $18(4.19 \%)$ trimers, $53(12.33 \%)$ tetramers, $8(1.86 \%)$ pentamers and $2(0.47 \%)$ hexamers (Fig. 2). Among the 430 SSRs, more than $81 \%$ repeats were belonged to monomers and dimers, which was nearly the same proportion $(80 \%)$ with that of Gossypium raimondii mt genome. Further analysis of the repeat unit of SSRs showed that $88.5 \%$ of monomers were A/T contents, whereas G/C only occupied $11.5 \%$. The higher AT contents in mononucleotide SSRs of S. suchowensis mt genome was in conformity with the high AT contents (55.02\%) in the complete S. suchowensis mt genome. The specific size and location of hexamers and pentamers were listed in Table 3, which showed that only one pentamer was located in a protein-coding gene (matR), one located in cis-intron (rps3), and the others were all located in the 


\section{Manuscript to be reviewed}

263 intergenic spacers. It is clearly that SSRs distributed in the protein-coding regions are

264 much less than non-coding areas, which account for $3.5 \%$ and $96.5 \%$, separately. In

265

266

267

268

269

270 non-coding areas, $8.8 \%$ of SSRs exists in the introns and $87.7 \%$ of SSRs exists in the intergenic spacers.

As illustrated in Table 4, we also identified a total of ten perfect tandem repeats with lengths ranging from $12 \mathrm{bp}$ to $28 \mathrm{bp}$ in the $S$. suchowensis $\mathrm{mt}$ genome. All of the ten tandem repeats were discovered in the intergenic spacers. Two long tandem repeats $(28 \mathrm{bp}$ ) were located in the $n a d 2 / r p l 10$ and $t r n P / r p s 4$ intergenic spacers, three in the same intergenic spacer of $c c m F n / a t p 8$, and the other five tandem repeats were distributed in the intergenic spacers of trnM-CAU/nad7, trnV-GAC/ccmFn, atp8/trnK-UUU, trnK-UUU/ccmFc and trnY-GUA/trnN-GUU, respectively. The results showed that SSRs and tandem repeats were principally concentrated in the intergenic spacer.

Apart from SSRs and tandem repeats, a total of 349 short and large repeats with the total length of $29,627 \mathrm{bp}$ ( $4.6 \%$ of the mt genome) were detected in the $S$. suchowensis $\mathrm{mt}$ genome. The short repeats represent less than $1 \mathrm{~kb}$, while the large repeats are longer than $1 \mathrm{~kb}$. As shown in Fig. 3, most of the repeats (164 repeats, $47 \%$ ) were ranged from $20 \mathrm{bp}$ to $29 \mathrm{bp}, 23.2 \%$ were $30 \mathrm{bp}$ to $39 \mathrm{bp}$ long, and fifteen repeats were longer than $100 \mathrm{bp}$ (Table 5), with only one longer than $1 \mathrm{~kb}$ (R1:15592 $\mathrm{bp})$. Among the fifteen repeats $(>100 \mathrm{bp})$, six of them were direct repeats, and nine were inverted repeats. Larger repeats are remarkable because they are associated with the changes of mitochondrial reversible genomic structure. Additionally, genes appearing in large repeats may generate multiple copies. In the S. suchowensis $\mathrm{mt}$ genome, we discovered only one gene of $r p s 7$ in R1 has an intact copy.

\section{RNA editing sites in the $S$. suchowensis mt genome}

Previous studies have identified that RNA editing is a posttranscriptional process, which converts specific Cytidines to Uridines in chloroplast and mitochondrial genomes of land plants (Bock \& Khan 2004; Chen et al. 2011; Raman \& Park 2015; Wakasugi et al. 1996; Zandueta-Criado \& Bock 2004). This RNA-editing process is prone to increase the protein conservation among higher plants by "correcting" codons. Exploiting this principle, the PREP-mt program was used to predict 330 RNA editing sites in 33 protein-coding genes (including one multicopy gene: rps7) of the $S$. suchowensis $\mathrm{mt}$ genome and $100 \% \mathrm{C}$ to U RNA editing. As illustrated in Fig. 4, nad4 encoded the most RNA-editing sites (37 sites), while up to five genes (atp8, atp9, $\operatorname{cox} 1, \operatorname{cox} 2$ and nad3) encoded none of RNA editing sites. Among these RNA editing sites, $36.1 \%$ (119 sites) occurred in the first base position of the codon, while $63.9 \%$ (211 sites) occurred in the second base position and none were in the third position. codon in protein-coding genes. Additionally, further study found that $46.7 \%$ (154 sites) 


\section{Manuscript to be reviewed}

303 (99 sites) from hydrophobic to hydrophobic, 14\% (46 sites) from hydrophilic to

304 hydrophilic, 9.1\% (30 sites) from hydrophobic to hydrophilic, and only one amino

305 acids of $c c m F c$ gene was converted from Arginine to a stop codon. Among these,

306 most of the amino acids tended to be converted from Serine to Leucine $(21.8 \%, 72$

307 sites), Proline to Leucine (20.3\%, 67 sites) and Serine to Phenylalanine (15.8\%, 52

308 sites). The remaining 139 RNA editing sites are distributed in other RNA editing types, 309 including Ala to Val, His to Tyr, Leu to Phe, Pro to Phe, Pro to Ser, Arg to Trp, Thr to

310 Met, Thr to Ile, and Arg to $\mathrm{X}(\mathrm{X}=$ stop codon $)$.

311 The substitution rates of protein-coding genes in the $S$.

\section{2 suchowensis mt genome}

313 In genetics, nonsynonymous $(\mathrm{Ka})$ and synonymous $(\mathrm{Ks})$ substitution rates is 314 significant for understanding evolutionary dynamics of protein-coding genes across 315 similar and yet diverged species. It has been widely known that $\mathrm{Ka} / \mathrm{Ks}$ indicate neutral 316 evolution when $\mathrm{Ka} / \mathrm{Ks}$ equals to 1 , positive selection when $\mathrm{Ka} / \mathrm{Ks}$ greater than 1 , and 317 negative selection when $\mathrm{Ka} / \mathrm{Ks}$ less than 1 . In this study, all of the 32 protein-coding 318 genes of S. suchowensis mt genome were used to calculate the Ka and Ks substitution 319 rates against the Gossypium raimondii $\mathrm{mt}$ genome. As shown in Fig. 5, the ratios of $320 \mathrm{Ka} / \mathrm{Ks}$ were significantly less than 1 in most of the protein-coding genes. Nevertheless, 321 the $\mathrm{Ka} / \mathrm{Ks}$ ratio of $\mathrm{ccmB}$ (1.21) was greater than 1, indicating that this gene may have 322 suffered from positive selection since the divergence of $S$. suchowensis and $G$. 323 raimondii from their last common ancestor (Bi et al. 2016). Additionally, two genes 324 (matR: 1.02, rps3: 0.97) were close to 1, indicating that they may have experienced 325 neutral evolution since the divergence of their common ancestor. Combining with 326 Table 1, the Fig. 5 also illustrated that the $\mathrm{Ka} / \mathrm{Ks}$ ratios of all the Complex genes and 327 Ribosomal proteins were all below 1, as well as a transport membrane protein $(m t t B)$, 328 indicating that purifying selection was acting on these genes, and these genes may be 329 highly conservative in the evolutionary process of higher plants.

\section{Migration of chloroplast DNA in mitochondrial genomes}

331 Without the full-length nuclear genome sequence of $S$. suchowensis, we cannot identify the DNA transfer between the nucleus and mitochondria. The S. suchowensis $\mathrm{mt}$ genome was searched against its available cp genome and the similar sequences were filtered, which resulted in 41 matched hits between the two genomes. The hits covered $11.3 \%(17.5 \mathrm{~kb})$ of the cp genome and $2.8 \%(18.1 \mathrm{~kb})$ of the $\mathrm{mt}$ genome. Interestingly, when the mt genome was searched against the representative seed plant cp genomes, the matched hits covered $3.2 \%(20.5 \mathrm{~kb})$ of the $\mathrm{mt}$ genome, suggesting that some sequences were lost from the $S$. suchowensis cp genome but were 


\section{Manuscript to be reviewed}

339 maintained by $\mathrm{mt}$ genome after the ancient chloroplast to mitochondrial transfers.

340 The protein-coding and tRNA genes transferred from $\mathrm{cp}$ to $\mathrm{mt}$ genomes were also 341 identified by NCBI-BLASTn with stringent parameters. The results showed that only

342 two complete cp protein-coding genes ( $a t p E$ and $p s b D)$ and nine tRNA genes 343 (trnD-GUC, trnH-GUG, trnK-GUG, trnM-CAU, trnN-GUU, trnS-GGA, trnV-GAC, $344 \operatorname{trn} W-C C A$ and $\operatorname{trn} Y-G U A$ ) were transferred to $m$ t genome (Table 1). Additionally, some partial cp protein-coding genes $(a c c D, a t p A, a t p B, \operatorname{clp} P, \operatorname{pet} B, p s a A, p s a B, p s b A$, $p s b B, p s b C, r p o B, r p s 12$ and $y c f 2$ ) were also transferred to the $\mathrm{mt}$ genome. The distinction of transferred genes between protein-coding and tRNA genes suggested that protein-coding genes could not survive completely during the evolution. However, tRNA genes were preserved probably because they played important roles in the $S$. suchowensis mt genome.

\section{Phylogenetic analysis within higher plant mt genomes}

Phylogenetic analyses were performed based on an aligned data matrix of 35 species and 23 protein-coding genes. As illustrated in Fig. 6, the 35 plant species were divided into four categories, including 19 rosids (Glycine max, Vigna angularis, Millettia pinnata, Lotus japonicus, Medicago truncatula, Vitis vinifera, Malus domestica, Gossypium hirsutum, Gossypium raimondii, Carica papaya, Batis maritima, Brassica napus, Arabidopsis thaliana, Raphanus sativus, Populus tremula, Salix suchowensis,

358 Citrullus lanatus, Cucumis sativus and Cucurbita pepo), 8 asterids (Daucus carota, Capsicum annuum, Nicotiana tabacum, Beta vulgaris, Ajuga reptans, Salvia miltiorrhiza, Asclepias syriaca and Rhazya stricta), 6 monocots (Butomus umbellatus, Phoenix dactylifera, Oryza sativa, Zea mays, Sorghum bicolor and Tripsacum dactyloides) and 2 gymnosperms (Cycas taitungensis and Ginkgo biloba). The two gymnosperms were designated as outgroup. Abbreviations of all these observed plant $\mathrm{mt}$ genomes are listed in Table S3. Bootstrap analysis showed that 27 of the 32 nodes were supported by values over $70 \%, 22$ out of 32 nodes with bootstrap values over $90 \%$ and 11 nodes supported by $100 \%$ bootstrap value (Fig. 6). The phylogenetic tree strongly supported the separation of rosids and asterids with $99 \%$ bootstrap value, as well as the separation of eudicots and monocots (100\%), and the separation of angiospermae and gymnospermae (100\%). Additionally, according to the NJ tree, $S$. suchowensis and P. tremula were classified into one clade (Salicaceae) with $100 \%$

371 bootstrap value, whereas this clade was a little different from other plant species in 372 rosids. 


\section{Manuscript to be reviewed}

373 Comparison of genomic features with other mitochondrial

374

375

376

377

378

379

380

381

382

383

384

385

386

387

388

389

390

391

392

393

394

395

396

397

398

399

400

401

402

403

404

405

406

407

408

409

410

411

412

\section{genomes}

With the rapid development of sequencing technology, more and more complete plant $\mathrm{mt}$ genomes have been assembled, which would provide an important opportunity to compare the genomic features within multiple plant species (Alverson et al. 2011; Wei et al. 2016). As described by Richardson et al. (Richardson et al. 2013), the plant mt genomes varied considerably in size, gene content and order, only the same genus sharing the similar genomic features. In genus Salix, another mt genome of Salix purpurea has been assembled. It is very important to make comparative genomic analyses between $S$. suchowensis and S. purpurea mt genome. As illustrated in Fig. 7, the size $(598,970 \mathrm{bp})$ and GC content $(44.94 \%)$ of $S$. purpurea are a little less than that of S. suchowensis mt genome (Alverson et al. 2011; Wei et al. 2016). What's more, the number of genes and introns in the two $\mathrm{mt}$ genomes are similar, with $S$. suchowensis having only one tRNA genes $(\operatorname{trn} H-A U G)$ annotated than that of $S$. purpurea. By comparing the genome physical map of $S$. purpurea and $S$. suchowensis $\mathrm{mt}$ genome, we found that gene orders of the two $\mathrm{mt}$ genomes were different from each other, whereas only a few gene orders were conserved during evolution. The conserved gene orders of the two mt genomes are as follows: nad7-trnV (4 genes), ccmFn-trnK (3 genes), trnY-ccmB (7 genes), rpll6-matR (13 genes), nad3-rps 7 (5 genes), atp6-trnS (3 genes) and trnP-rps 7 (4 genes). From Table S4, we found that nearly all of the $S$. suchowensis $\mathrm{mt}$ genome sequence showed a high similarity (most identity $>99 \%$ ) with that of $S$. purpurea $\mathrm{mt}$ genome, and the longest syntenic blocks was $143,567 \mathrm{bp}$. The extremely high identities between $S$. suchowensis and $S$. purpurea $\mathrm{mt}$ genome suggest that the differentiation of the two Salix species must be very recent during the evolution of plants.

Additionally, we also compared the sizes and GC contents of 22 land plant $\mathrm{mt}$ genomes (Fig. 7), including 5 bryophytes (Buxbaumia aphylla, Bartramia pomiformis, Sphagnum palustre, Treubia lacunosa and Marchantia polymorpha), 2 gymnosperms (Ginkgo biloba and Cycas taitungensis), 5 monocots (Triticum aestivum, Sorghum bicolor, Oryza sativa, Zea mays and Phoenix dactylifera) and 8 dicots (Arabidopsis thaliana, Citrullus lanatus, Glycine max, Nicotiana tabacum, Salix suchowensis, Salix purpurea, Gossypium raimondii, Populus tremula, Cucurbita pepo and Cucumis sativus). The abbreviation of all these observed plant $\mathrm{mt}$ genomes are listed in Table S3. The sizes of our observed plant $\mathrm{mt}$ genomes vary from $100,725 \mathrm{bp}$ in B. aphylla to $1,555,935$ bp in $C$. sativus, while the size of $S$. suchowensis $(644,437 \mathrm{bp}) \mathrm{mt}$ genome is in the middle of these observed plants. Similarly, the GC contents are also variable, ranging from $38.99 \%$ in $S$. palustre to $50.36 \%$ in G. biloba. Additionally, the GC contents of angiosperms, including monocots and dicots, are larger than that of bryophytes but smaller than that of gymnosperms, suggesting that the GC contents changed frequently since the divergence of bryophytes, gymnosperms and

Peer) reviewing PDF | (2017:01:15495:2:0:NEW 27 Feb 2017) 
413 angiosperms. However, the GC contents in angiosperms were conserved during the

414 evolution, despite their genome sizes varied tremendously.

415 In the $S$. suchowensis mt genome, a total of 23 introns, including 17 cis-introns and

4166 trans-introns, were discovered in nine genes. Among the nine intron-containing

417 genes, three of which (nad1, nad2 and nad5) require cis-splicing as well as

418 trans-splicing events to maturate, while atpl only requires trans-splicing event and

419 the other five genes ( $n a d 4, n a d 7, r p l 2, c c m F c$ and $r p s 3$ ) only require $c i s$-splicing

420 event to maturate (Table 6). During the evolution of seed plant mt genomes, genes

421 containing introns were conserved, as well as the numbers of cis- or trans-introns.

422 Table 6 compared the number of cis- and trans- introns in four seed plant mt genomes, 423 including one gymnosperm (G. biloba), one monocot ( $T$. aestivum), and two dicots ( $P$. 424 tremula and S. suchowensis). As illustrated in Table 6, G. biloba contains 20 cis- and 4255 trans-introns, T. aestivum contains 19 cis- and 6 trans-introns, and P. tremula 426 contains 17 cis- and 5 trans- introns. The numbers of introns in nad2, nad4, nad5 and $427 \quad$ nad7 are extremely conserved, but there are still some introns lost or maintained 428 during the evolution. For example, a trans-intron in atpl was lost from G. biloba, T. 429 aestivum, P. tremula but maintained by S. suchowensis; a cis-intron in rps 10 was 430 maintained by T. aestivum but lost from the others. Additionally, one or two 431 cis-introns in cox 2 were lost from Salicaceae during the evolution. Overall, the 432 locations and numbers of introns in the S. suchowensis mt genome were rather well 433 conserved as in other complete seed plant mt genomes.

434 Previous studies revealed that the length of homologous sequences among different 435 plant $\mathrm{mt}$ genomes was consistent with taxonomies, despite the unique variability 436 among these $\mathrm{mt}$ genomes ( $\mathrm{Li}$ et al. 2009b). The closely related species always share 437 the greatest sequences, even in the non-coding regions, while species belong to different families share fewer ( $\mathrm{Li}$ et al. 2009b). During the evolution of plant $\mathrm{mt}$ genomes, the loss and acquisition of protein-coding and tRNA genes occurred frequently. Table 7 compared the protein-coding and tRNA genes of five representative plant mt genomes. According to Table 1 and Table 7, we found that the numbers of protein-coding genes in $\mathrm{mt}$ genomes tend to decrease during the evolution of plants. In these observed plant $\mathrm{mt}$ genomes, most of the protein-coding genes were conserved in different plant $\mathrm{mt}$ genomes, however, the ribosomal proteins were highly variable. The rpl5 gene was only lost in Salicaceae but existed in other observed plant $\mathrm{mt}$ genomes, while the rpllo gene was only found in Salicaceae but lost in others. Three ribosomal proteins ( $r p s 2$, rps 13 and rps19) seemed to have been lost in eudicots after the differentiation of eudicots and monocots. The $r p l 6$ and $r p s 8$ genes probably, only existed in M. polymorpha, were lost in angiosperms and gymnosperms during the evolution. Strikingly, some functional genes changed into pseudo genes during the evolution, such as rpl16 in P. tremula, nad7 in M. polymorpha, as well as rps 11 and rps14 in O. sativa. Previous studies have shown that the corresponding mitochondrial rps 2 and rps 11 genes have been transferred to the nucleus in Arabidopsis, soybean and tomato, suggesting that gene loss events followed by functional transfer to the 
455 nucleus(Palmer et al. 2000; Perrotta et al. 2002). Most ribosome protein genes are

456 frequently absent in clades of angiosperm $\mathrm{mt}$ genomes, which can be considered

457 unnecessary to some extent (Shengxin et al. 2013). Apart from ribosomal proteins,

458 succinate dehydrogenase genes were usually lost in angiosperms. A previous study by

459 Southern blot survey of multiple angiosperms showed that the losses of $s d h 4$ genes

460 were focused on the monocots, and no losses were detected in basal angiosperms

461 (Adams et al. 2001). More specially, contrasting with G. biloba and M. polymorpha,

462 plant species in angiosperms have lost $s d h 3$ genes, which can be inferred as $s d h 3$

463 gradually lost or developed into pseudo genes during the evolution of angiosperms.

464 Previous studies proposed that genes losses rarely occurred with respiratory genes and 465 most genes occurred with ribosomal proteins (Shengxin et al. 2013), which were

466 given support by our data.

467 The protein synthesis of plant $\mathrm{mt}$ genomes requires an entire set of tRNA genes,

468 including $\operatorname{trn} A, \operatorname{trn} C, \operatorname{trn} D, \operatorname{trn} E, \operatorname{trn} F, \operatorname{trn} G, \operatorname{trn} H, \operatorname{trn} I, \operatorname{trn} K, \operatorname{trn} L, \operatorname{trn} M, \operatorname{trn} N, \operatorname{trn} P$,

$469 \operatorname{trn} Q, \operatorname{trnR}, \operatorname{trn} S, \operatorname{trn} T, \operatorname{trn} V, \operatorname{trn} W, \operatorname{trn} Y$ and $\operatorname{trnf} M$. However, a large number of tRNA

470 genes experienced inactivation, loss or migration during the evolution of plant $\mathrm{mt}$

471 genomes (Dietrich et al. 1996). As shown in Table 7, six tRNA genes (trnA-UGC,

472 trnG-UCC, trnL-CAA, trnR-UCG, trnT-GGU and trnV-UAC) were lost in all observed

473 plants except $M$. polymorpha, suggesting that this loss event probably occurred in the

474 differentiation of bryophytes and gymnosperms. Additionally, four tRNA genes

475 (trnL-UAG, trnL-UAA, trnR-ACG and trnR-UCU) were lost from gymnosperms to

476 angiosperms. Specially, five kinds of tRNA genes ( $\operatorname{trn} A, \operatorname{trn} I, \operatorname{trn} L, \operatorname{trn} R$ and $\operatorname{trn} T)$

477 were lost from the $S$. suchowensis $\mathrm{mt}$ genome, suggesting that tRNA genes importing

478 from cytosol must be invoked as the mechanism for making up the deficit (Kubo et al.

479 2000). Identification of the number and types of tRNA genes in S. suchowensis $\mathrm{mt}$

480 genome will be helpful to evaluate the origin and evolution of tRNA genes in higher

481 plants. Consequently, the above results powerfully suggest that intracellular genes of

482 ribosomal protein and tRNA genes transfer from mitochondria to the nuclear genome

483 are a frequent process. In return, this can also allow the nucleus to control the

484 organelle by encoding organelle-destined proteins (Schneider 2014; Woodson \&

485 Joanne 2008).

486 In summary, based on the comparison of protein-coding and tRNA genes with other

$487 \mathrm{mt}$ genomes, the $S$. suchowensis $\mathrm{mt}$ genome has lost 14 genes, including 9

488 protein-coding genes (rpl5, rps 1, rps2, rps10, rps11, rps13, rps 14, rps19 and $s d h 3), 4$

489 tRNA genes (trnL-UAA, trnL-UAG, trnR-ACG and trnR-UCU), when compared with

490 the representative gymnosperm G. biloba. The 9 protein-coding genes, except rps 1 ,

491 also can not be found in another Salicaceae mt genome P. tremula. Previous studies in

492 other plant $\mathrm{mt}$ genomes showed that a few lost $\mathrm{mt}$ genes were found to have

493 transferred into the nuclear genomes (Adams et al. 2000; Adams et al. 2002; Adams et

494 al. 2001). Thus, the genes lost may be considered as redundant genes for $S$.

495 suchowensis $\mathrm{mt}$ genome or their functions can be duplicated by other genes, which is

496 an evolutionary compaction of the $\mathrm{mt}$ genome in seed plants. 


\section{Manuscript to be reviewed}

\section{Conclusions}

498 In this study, the complete mt genome of $S$. suchowensis shares most of the common

499 genomic features with other plant $\mathrm{mt}$ genomes. The identification of RNA editing

500 sites will provide important clues for predicting gene functions with novel codons.

$501 \mathrm{The} \mathrm{Ka} / \mathrm{Ks}$ analysis and the comparison of genomic features with other plant $\mathrm{mt}$

502 genomes should be contribute to a comprehensive understanding of plant mt evolution.

503 Mitochondria are very important for plant breeding. With the accomplishment of the

$504 \mathrm{mt}$ genome of $S$. suchowensis and further development of the next and third

505 generation sequencing platforms, we also have an opportunity to conduct further

506 genomic breeding studies in willow.

\section{Acknowledgement}

508 The authors are deeply grateful to Changwei Bi and Xuelin Wang, who performed the

509 experiment and provided valuable suggestions to this manuscript. The authors thank

510 Juan Li and Dongyang Wu for their contributions in annotating and analyzing the

511 mitochondrial genome, and we also thank Yiqing Xu and Qiaolin Ye for drawing

512 some figures.

\section{References}

514 Adams KL, Daley DO, Qiu YL, Whelan J, ., and Palmer JD. 2000. Repeated, recent 515 and diverse transfers of a mitochondrial gene to the nucleus in flowering plants. Nature 408:354-357.

Adams KL, Qiu YL, Stoutemyer M, and Palmer JD. 2002. Punctuated evolution of mitochondrial gene content: high and variable rates of mitochondrial gene loss and transfer to the nucleus during angiosperm evolution. Proc Natl Acad Sci USA. Proceedings of the National Academy of Sciences 99:9905-9912.

Adams KL, Rosenblueth M, ., Qiu YL, and Palmer JD. 2001. Multiple losses and transfers to the nucleus of two mitochondrial succinate dehydrogenase genes during angiosperm evolution. Genetics 158:1289-1300.

Alverson AJ, Wei X, Rice DW, Stern DB, Barry K, and Palmer JD. 2010. Insights into the evolution of mitochondrial genome size from complete sequences of Citrullus lanatus and Cucurbita pepo (Cucurbitaceae). Molecular Biology and Evolution 27:1436-1448. 10.1093/molbev/msq029

531

Alverson AJ, Zhuo S, Rice DW, Sloan DB, and Palmer JD. 2011. The mitochondrial genome of the legume Vigna radiata and the analysis of recombination across short mitochondrial repeats. PLoS One 6:e16404. 10.1371/journal.pone.0016404 
532 Benson $\mathrm{G}$, . 1999. Tandem repeats finder: a program to analyze DNA sequences.

$533 \quad$ Nucleic acids research 27:573-580(578).

534

535

536

537

538

539

540

541

542

543

544

545

546

547

548

549

550

551

552

553

554

555

556

557

558

559

560

561

562

563

564

565

566

567

568

569

570

571

572

573

Bi C, Paterson AH, Wang X, Xu Y, Wu D, Qu Y, Jiang A, Ye Q, and Ye N. 2016. Analysis of the Complete Mitochondrial Genome Sequence of the Diploid Cotton Gossypium raimondii by Comparative Genomics Approaches. Biomed Res Int 2016:18. 10.1155/2016/5040598

Birky CW. 1995. Uniparental inheritance of mitochondrial and chloroplast genes: mechanisms and evolution. Proceedings of the National Academy of Sciences 92:11331-11338.

Bock R, and Khan MS. 2004. Taming plastids for a green future. Trends Biotechnol 22:311-318. 10.1016/j.tibtech.2004.03.005

Buhler JD, Lancaster JM, Jacob AC, and Chamberlain RD. 2007. Mercury BLASTN: Faster DNA sequence comparison using a streaming hardware architecture. in Proc of Reconfigurable Systems Summer Institute.

Chang S, Wang Y, Lu J, Gai J, Li J, Chu P, Guan R, and Zhao T. 2013. The mitochondrial genome of soybean reveals complex genome structures and gene evolution at intercellular and phylogenetic levels. PLoS One 8:e56502. 10.1371/journal.pone.0056502

Chen C, Zhou P, Choi Y, and Huang S, Fg. 2006. Mining and characterizing microsatellites from citrus ESTs. Tagtheoretical \& Applied Geneticstheoretische Und Angewandte Genetik 112:1248-1257.

Chen H, Deng L, Jiang Y, Lu P, and Yu J. 2011. RNA editing sites exist in protein-coding genes in the chloroplast genome of Cycas taitungensis. J Integr Plant Biol 53:961-970. 10.1111/j.1744-7909.2011.01082.x

Dai X, Hu Q, Cai Q, Feng K, Ye N, Tuskan GA, Milne R, Chen Y, Wan Z, Wang Z, Luo W, Wang K, Wan D, Wang M, Wang J, Liu J, and Yin T. 2014. The willow genome and divergent evolution from poplar after the common genome duplication. Cell Res 24:1274-1277. 10.1038/cr.2014.83

Dietrich A, Small I, Cosset A, Weil JH, and Maréchal-Drouard L. 1996. Editing and import: Strategies for providing plant mitochondria with a complete set of functional transfer RNAs. Biochimie 78:518-529.

Edgar RC. 2004. MUSCLE: multiple sequence alignment with high accuracy and high throughput. Nucleic Acids Res 32:1792-1797. 10.1093/nar/gkh340

Fujii S, Kazama T, Yamada M, and Toriyama K. 2010. Discovery of global genomic re-organization based on comparison of two newly sequenced rice mitochondrial genomes with cytoplasmic male sterility-related genes. Bmc Genomics 11:1-15.

Greiner S, and Bock R. 2013. Tuning a ménage à trois: Co-evolution and co-adaptation of nuclear and organellar genomes in plants. Drug \& Alcohol Dependence 35:354-365.

Handa H. 2003. The complete nucleotide sequence and RNA editing content of the mitochondrial genome of rapeseed (Brassica napus L.): comparative analysis 
574

575

576

577

578

579

580

581

582

583

584

585

586

587

588

589

590

591

592

593

594

595

596

597

598

599

600

601

602

603

604

605

606

607

608

609

610

611

612

613

614

615

of the mitochondrial genomes of rapeseed and Arabidopsis thaliana. Nucleic Acids Res 31:5907-5916. 10.1093/nar/gkg795

Hsu CL, and Mullin BC. 1989. Physical characterization of mitochondrial DNA from cotton. Plant Molecular Biology 13:467-468.

Ji M, Bingxian Y, Wei Z, Lianli S, Jingkui T, and Xumin W. 2013. The complete chloroplast genome sequence of Mahonia bealei (Berberidaceae) reveals a significant expansion of the inverted repeat and phylogenetic relationship with other angiosperms. Gene 528:120-131.

Keeling PJ. 2010. The endosymbiotic origin, diversification and fate of plastids. Philosophical Transactions of the Royal Society of London 365:729-748.

Kersten B, Faivre RP, Mader M, Le PM, Bounon R, Berard A, Vettori C, Schroeder H, Leplé JC, and Fladung M. 2016. Genome Sequences of Populus tremula Chloroplast and Mitochondrion: Implications for Holistic Poplar Breeding. PloS one 11.

Knoop V. 2004. The mitochondrial DNA of land plants: Peculiarities in phylogenetic Perspective. Current Genetics 46:123-139.

Kubo T, ., Nishizawa S, ., Sugawara A, ., Itchoda N, ., Estiati A, ., and Mikami T, . 2000. The complete nucleotide sequence of the mitochondrial genome of sugar beet (Beta vulgaris L.) reveals a novel gene for tRNA(Cys)(GCA). Nucleic acids research 28:2571-2576.

Li H, and Durbin R. 2009. Fast and accurate short read alignment with Burrows-Wheeler transform. Bioinformatics 25:1754-1760. 10.1093/bioinformatics/btp324

Li H, Handsaker B, Wysoker A, Fennell T, Ruan J, Homer N, Marth G, Abecasis G, Durbin R, and Genome Project Data Processing S. 2009a. The Sequence Alignment/Map format and SAMtools. Bioinformatics 25:2078-2079. 10.1093/bioinformatics/btp352

Li L, Wang B, Liu Y, and Qiu YL. 2009b. The complete mitochondrial genome sequence of the hornwort Megaceros aenigmaticus shows a mixed mode of conservative yet dynamic evolution in early land plant mitochondrial genomes. Journal of Molecular Evolution 68:665-678.

Librado P, and Rozas J. 2009. DnaSP v5: a software for comprehensive analysis of DNA polymorphism data. Bioinformatics 25:1451-1452. 10.1093/bioinformatics/btp187

Liu J, Yin T, Ye N, Chen Y, Yin T, Liu M, and Hassani D. 2013. Transcriptome analysis of the differentially expressed genes in the male and female shrub willows (Salix suchowensis). PLoS One 8:e60181. 10.1371/journal.pone.0060181

Lohse M, Drechsel O, and Bock R. 2007. OrganellarGenomeDRAW (OGDRAW): A tool for the easy generation of high-quality custom graphical maps of plastid and mitochondrial genomes. Current Genetics 52:267-274.

Lonsdale DM, Brears T, Hodge TP, Melville SE, and Rottmann WH. 1988. The Plant

Peer) reviewing PDF | (2017:01:15495:2:0:NEW 27 Feb 2017) 
616

617

618

619

620

621

622

623

624

625

626

627

628

629

630

631

632

633

634

635

636

637

638

639

640

641

642

643

644

645

646

647

648

649

650

651

652

653

654

655

656

657

Mitochondrial Genome: Homologous Recombination as a Mechanism for Generating Heterogeneity. Philosophical Transactions of the Royal Society B Biological Sciences 319:149-163.

Mower JP. 2009. The PREP suite: predictive RNA editors for plant mitochondrial genes, chloroplast genes and user-defined alignments. Nucleic Acids Res 37:W253-259. 10.1093/nar/gkp337

Oda K, ., Yamato K, ., Ohta E, ., Nakamura Y, ., Takemura M, ., Nozato N, ., Akashi K, ., and Ohyama K, . 1992. Transfer RNA genes in the mitochondrial genome from a liverwort, Marchantia polymorpha: the absence of chloroplast-like tRNAs. Nucleic Acids Res 20:3773-3777.

Palmer JD, Adams KL, Cho Y, ., Parkinson CL, Qiu YL, and Song K, . 2000. Dynamic evolution of plant mitochondrial genomes: mobile genes and introns and highly variable mutation rates. Proceedings of the National Academy of Sciences of the United States of America 97:35-57.

Palmer JD, and Herbon LA. 1988. Plant mitochondrial DNA evolves rapidly in structure, but slowly in sequence. Journal of Molecular Evolution 28:87-97.

Perrotta G, Grienenberger JM, and Gualberto JM. 2002. Plant mitochondrial rps2 genes code for proteins with a C-terminal extension that is processed. Plant Molecular Biology 50:523-533.

Raman G, and Park S. 2015. Analysis of the Complete Chloroplast Genome of a Medicinal Plant, Dianthus superbus var. longicalyncinus, from a Comparative Genomics Perspective. PLoS One 10:e141329. 10.1371/journal.pone.0141329

Richardson AO, and Palmer JD. 2007. Horizontal gene transfer in plants. J Exp Bot. Journal of Experimental Botany 58:1-9.

Richardson AO, Rice DW, Young GJ, Alverson AJ, and Palmer JD. 2013. The "fossilized" mitochondrial genome of Liriodendron tulipifera : ancestral gene content and order, ancestral editing sites, and extraordinarily low mutation rate. Bmc Biology 11:1-17.

Sagan L. 1967. On the origin of mitosing cells. Journal of Theoretical Biology 14:255-274.

Schattner P, Brooks AN, and Lowe TM. 2005. The tRNAscan-SE, snoscan and snoGPS web servers for the detection of tRNAs and snoRNAs. Nucleic acids research 33:W686-W689.

Schneider A. 2014. Dominance of cytolytic effector functions in hepatitis B virus-specific $\mathrm{CD} 8+\mathrm{T}$ cell and $\mathrm{NK}$ cell mediated antiviral efficacy using hepatitis B virus infected hepatocytes overexpressing human sodium taurocholate cotransporting polypeptide. Zeitschrift Für Gastroenterologie.

Schuster W, Hiesel R, and Brennicke A. 1990. RNA editing in plant mitochondria. Science 246:1632-1634.

Shengxin C, Yankun W, Jiangjie L, Junyi G, Jijie L, Pu C, Rongzhan G, and Tuanjie Z. 2013. The mitochondrial genome of soybean reveals complex genome

Peer] reviewing PDF | (2017:01:15495:2:0:NEW 27 Feb 2017) 


\section{Manuscript to be reviewed}

658

659

660

661

662

663

664

665

666

667

668

669

670

671

672

673

674

675

676

677

678

679

680

681

682

683

684

685

686

687

688

689

690

691

692

693

694

695

696

697

698

699 structures and gene evolution at intercellular and phylogenetic levels. PloS one 8:e56502.

Skippington E, Barkman TJ, Rice DW, and Palmer JD. 2015. Miniaturized mitogenome of the parasitic plant Viscum scurruloideum is extremely divergent and dynamic and has lost all nad genes. Proceedings of the National Academy of Sciences 112:E3515.

Sloan DB, Alverson AJ, Chuckalovcak JP, Wu M, Mccauley DE, Palmer JD, and Taylor DR. 2012. Rapid Evolution of Enormous, Multichromosomal Genomes in Flowering Plant Mitochondria with Exceptionally High Mutation Rates. PLoS Biol 10:e1001241.

Smith DR. 2014. Mitochondrion-to-plastid DNA transfer: it happens. New Phytologist 202:736.

Stern DB, and Lonsdale DM. 1982. Mitochondrial and chloroplast genomes of maize have a 12-kilobase DNA sequence in common. Nature 299:698-702.

Stettler RF, Bradshaw HD, Heilman PE, and Hinckley TM. 1996. Biology of Populus and its Implications for Management and Conservation: NRC Research Press.

Tamura K, Stecher G, Peterson D, Filipski A, and Kumar S. 2013. MEGA6: Molecular Evolutionary Genetics Analysis version 6.0. Molecular Biology and Evolution 30:2725-2729. 10.1093/molbev/mst197

Thiel T, Michalek W, Varshney R, and Graner A. 2003. Exploiting EST databases for the development and characterization of gene-derived SSR-markers in barley ( Hordeum vulgare L.). Tagtheoretical \& Applied Geneticstheoretische Und Angewandte Genetik 106:411-422.

Thompson JD, Gibson TJ, and Higgins DG. 2002. Multiple Sequence Alignment Using ClustalW and ClustalX. Chapter 2:2.3.1-2.3.22.

Tuskan GA, Difazio S, ., Jansson S, ., Bohlmann J, ., Grigoriev I, ., Hellsten U, ., Putnam N, ., Ralph S, ., Rombauts S, ., and Salamov A, . 2006. The genome of black cottonwood, Populus trichocarpa (Torr. \& Gray). Science 313:1596-1604.

Wakasugi T, Hirose T, Horihata M, Tsudzuki T, Kossel H, and Sugiura M. 1996. Creation of a novel protein-coding region at the RNA level in black pine chloroplasts: the pattern of RNA editing in the gymnosperm chloroplast is different from that in angiosperms. Proceedings of the National Academy of Sciences 93:8766-8770. 10.1073/pnas.93.16.8766

Ward BL, Anderson RS, and Bendich AJ. 1981. The mitochondrial genome is large and variable in a family of plants (cucurbitaceae). Cell 25:793-803.

Wei S, Wang X, Bi C, Xu Y, Wu D, and Ye N. 2016. Assembly and analysis of the complete Salix purpurea L. (Salicaceae) mitochondrial genome sequence. SpringerPlus 5:1894. 10.1186/s40064-016-3521-6

Wolfe KH, Li WH, and Sharp PM. 1987. Rates of nucleotide substitution vary greatly among plant mitochondrial, chloroplast, and nuclear DNAs. Proceedings of the National Academy of Sciences of the United States of America 
84:9054-9058.

701 Woodson JD, and Joanne C. 2008. Coordination of gene expression between organellar and nuclear genomes. Nature Reviews Genetics 9:383-395.

Wu Z. 2014. The whole chloroplast genome of shrub willows ( Salix suchowensis ). Mitochondrial Dna the Journal of Dna Mapping Sequencing \& Analysis:1-2. Yang L, Jia-Yu X, Bin W, Libo L, and Yin-Long Q. 2011. The mitochondrial genomes of the early land plants Treubia lacunosa and Anomodon rugelii: dynamic and conservative evolution. PloS one 6:: e25836.

Yasunari O, Yukiko Y, Koji M, Akira K, Toru T, Takashi S, Naohiko M, Shuhei N, Chiharu N, and Naoki M. 2005. Structural dynamics of cereal mitochondrial genomes as revealed by complete nucleotide sequencing of the wheat mitochondrial genome. Nucleic acids research 33:6235-6250. addition of non-encoded nucleotides and polysome association of mRNAs with an unedited start codon. Nucleic Acids Res 32:542-550. $10.1093 /$ nar/gkh217

Zhang T, Zhang X, Hu S, and Yu J. 2011. An efficient procedure for plant organellar genome assembly, based on whole genome data from the 454 GS FLX 719 sequencing platform. Plant Methods 7:1-8. 


\section{Figure 1 (on next page)}

The circular mitochondrial genome of S. suchowensis.

Genomic features on transcriptionally clockwise and counter-clockwise strands are drawn on the inside and outside of the circle, respectively. Genes belonging to different functional groups are color-coded. GC content is represented on the inner circle by the dark gray plot. 


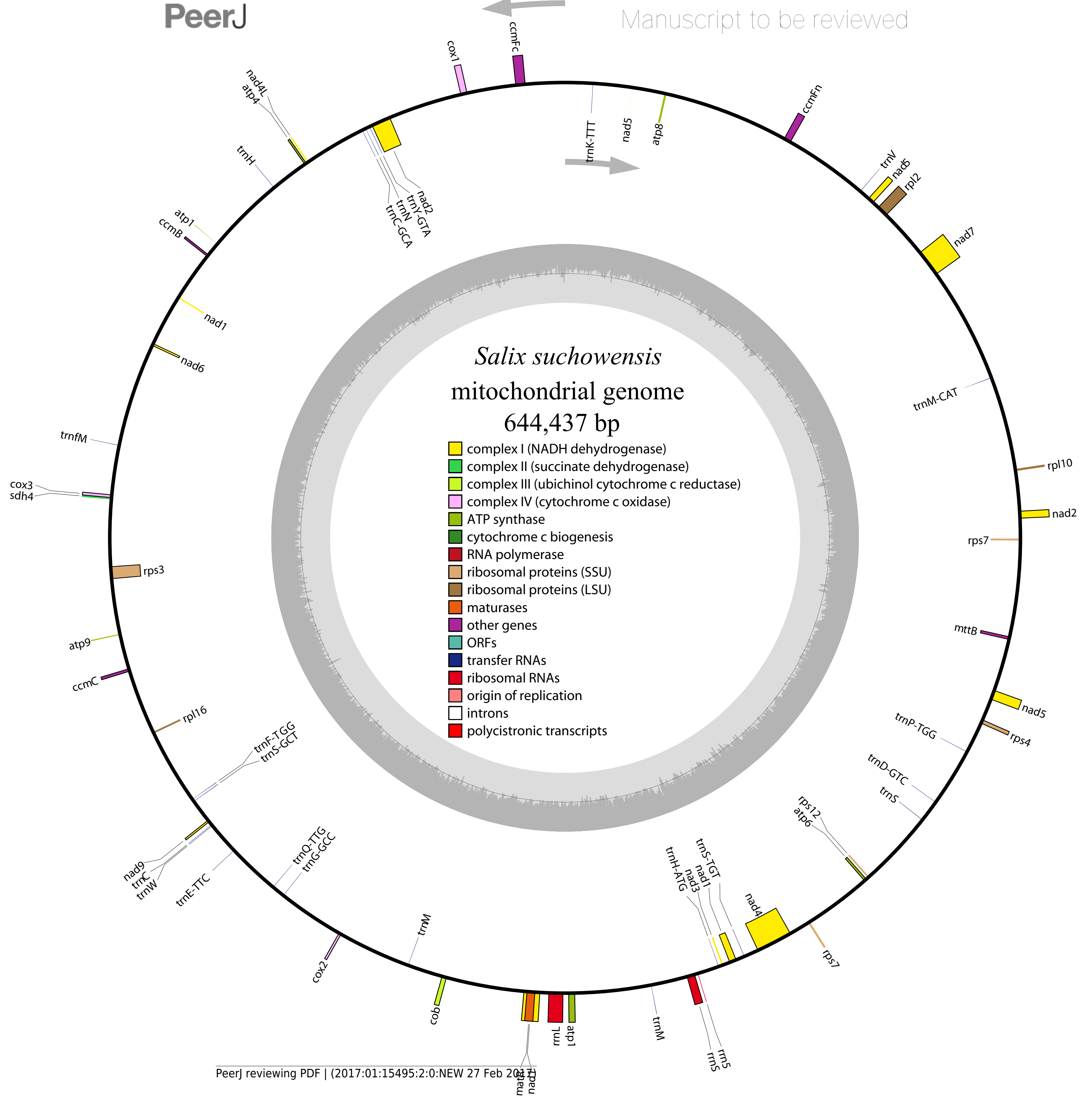




\section{Figure 2 (on next page)}

The distribution of SSRs in the S. suchowensis mt genome.

The colors represent different types of SSRs. The percentages of SSRs are also provided on the pie chart. 


\section{$0.47 \%$}

$1.86 \%$

$12.33 \%$

\section{$4.19 \%$}

\section{$42.09 \%$}

$39.07 \%$

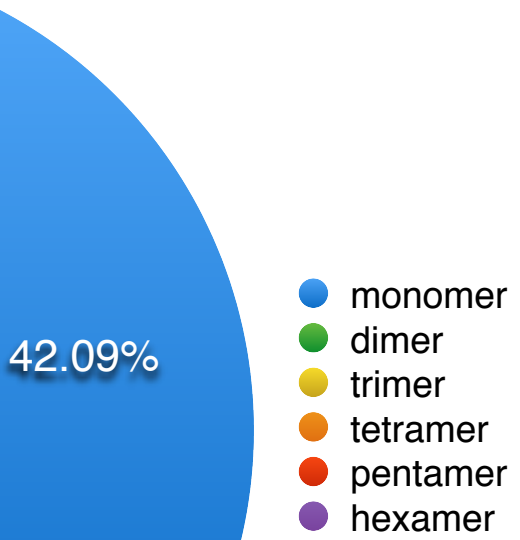




\section{Figure 3 (on next page)}

The frequency distribution of repeat lengths in the S. suchowensis mt genome.

The number shown in histogram represents the specific frequency of each repeat length. 
Figure 4 (on next page)

The distribution of RNA editing sites in the $S$. suchowensis mt protein-coding genes.

The number shown by gray box represents the RNA editing sites of each gene. 


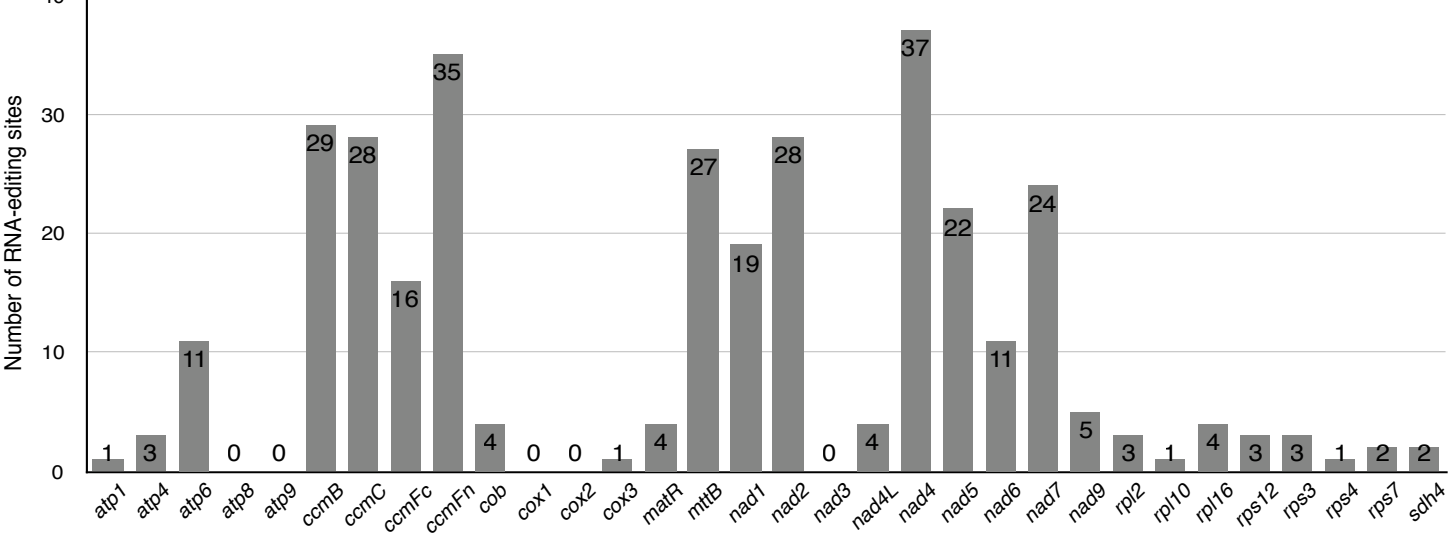




\section{Figure 5 (on next page)}

The $\mathrm{Ka} / \mathrm{Ks}$ values of 32 protein-coding genes of $\mathrm{S}$. suchowensis versus $\mathrm{G}$. raimondii.

The red, blue, green and purple genes indicate Complex genes, Cytochrome $\mathrm{c}$ biogenesis, Transport membrane protein and Ribosomal proteins, respectively. 


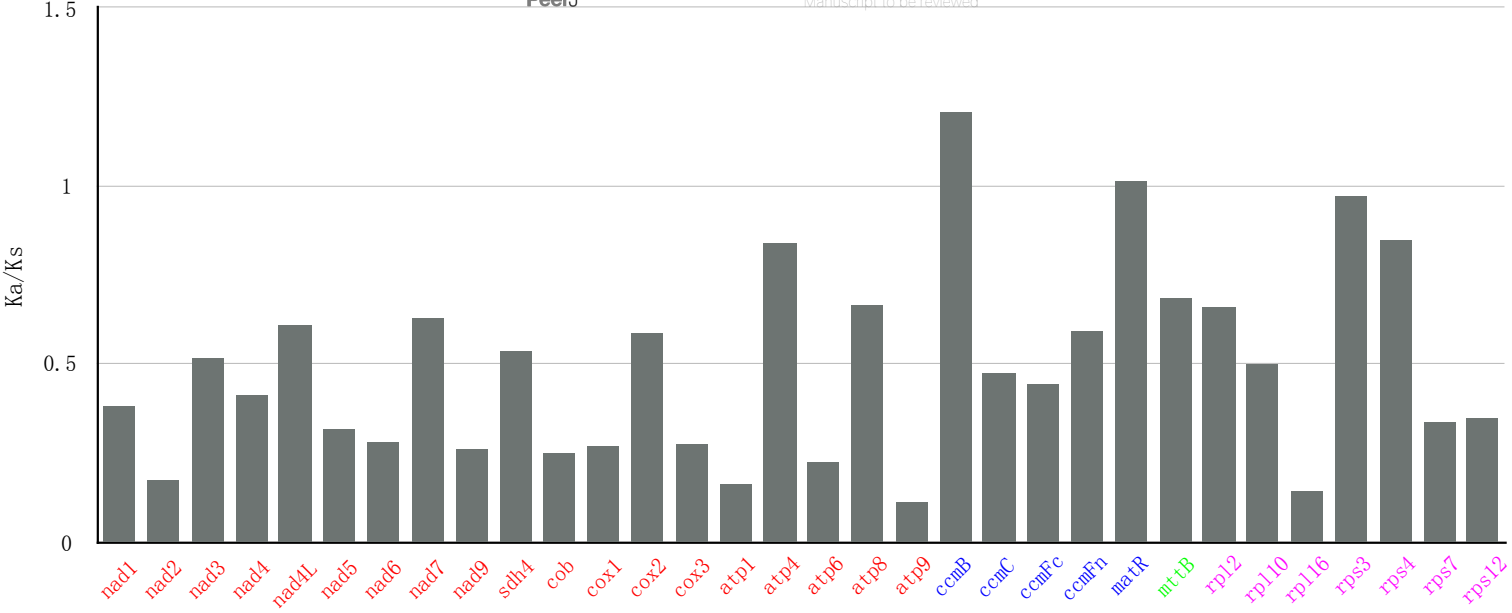




\section{Figure 6 (on next page)}

The Neighbor-Joining tree was constructed based on 23 conserved genes of 35 representative plant $\mathrm{mt}$ genomes.

The colors of red, blue, green and black circles represent the classes of rosids, asterids, monocots and gymnosperms. Numbers at the nodes are bootstrap support values. 


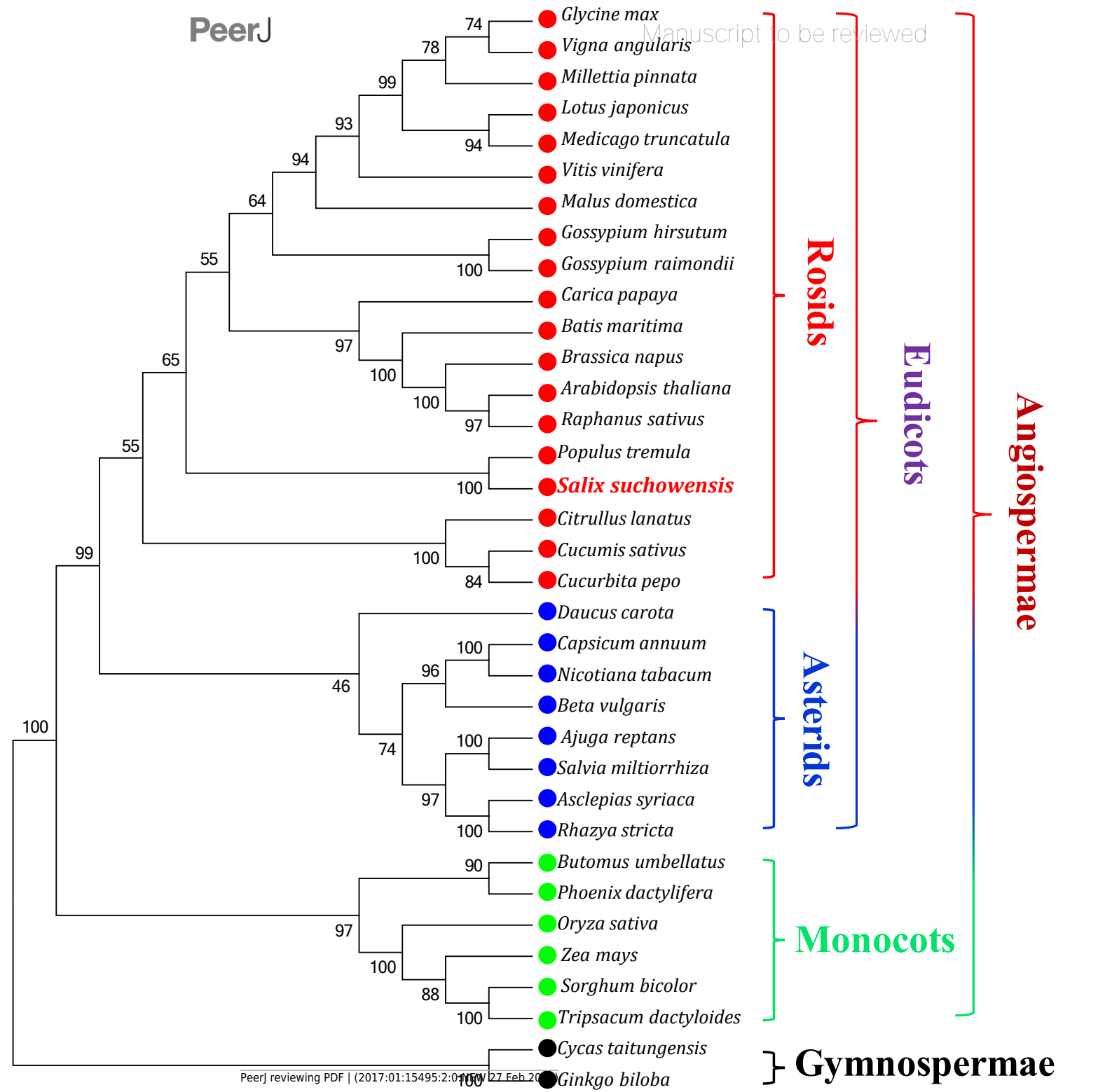




\section{Figure 7 (on next page)}

Comparison of sizes and GC contents within 22 land plant mt genomes.

The blue and green broken lines represent the sizes and GC contents, respectively. The colors of green, black, blue and red indicate different species in Bryophyte, Gymnospermae, Monocotyledoneae and Dicotledonae, respectively. 


\section{Table 1 (on next page)}

Gene profile and organization of the Salix Suchowensis mitogenome. 
1 Table 1. Gene profile and organization of the Salix Suchowensis mitogenome.

\begin{tabular}{|c|c|c|c|c|c|}
\hline Group of genes & Gene Name & Length & $\begin{array}{l}\text { Start } \\
\text { codon }\end{array}$ & $\begin{array}{c}\text { Stop } \\
\text { codon }\end{array}$ & $\begin{array}{c}\text { Amino } \\
\text { acid }\end{array}$ \\
\hline \multirow{5}{*}{ ATP synthase } & atpl & 1596 & ATG & TGA & 531 \\
\hline & atp4 & 597 & ATG & TAG & 198 \\
\hline & atp6 & 714 & ATG & TAA & 237 \\
\hline & atp 8 & 474 & ATG & TAG & 157 \\
\hline & atp9 & 225 & ATG & TAG & 75 \\
\hline \multirow{4}{*}{ Cytochrome $\mathrm{c}$ biogenesis } & $c c m B$ & 615 & ATG & TGA & 204 \\
\hline & $\operatorname{ccm} C$ & 753 & ATG & TGA & 251 \\
\hline & $c c m F c^{a}$ & 1362 & ATG & TAG & 453 \\
\hline & $c c m F n$ & 1725 & ATG & TGA & 575 \\
\hline Ubichinol cytochrome c reductase & $c o b$ & 1182 & ATG & TGA & 393 \\
\hline \multirow{3}{*}{ Cytochrome c oxidase } & $\operatorname{cox} 1$ & 1584 & ATG & TAA & 527 \\
\hline & $\cos 2$ & 675 & ATG & TAA & 224 \\
\hline & $\operatorname{cox} 3$ & 798 & ATG & TGA & 266 \\
\hline Maturases & matR & 1944 & ATG & TAG & 647 \\
\hline Transport membrane protein & $m t t B$ & 786 & ND & TAG & 261 \\
\hline \multirow{9}{*}{ NADH dehydrogenase } & $n a d 1^{a}$ & 885 & ATG & TAA & 295 \\
\hline & $\operatorname{nad} 2^{a}$ & 1461 & ATG & TAA & 486 \\
\hline & $\operatorname{nad} 3$ & 357 & ATG & TAA & 118 \\
\hline & $n a d 4^{a}$ & 1485 & ATG & TGA & 495 \\
\hline & nad $4 L$ & 303 & ATG & TAA & 100 \\
\hline & $n a d 5^{a}$ & 2004 & ATG & TAA & 667 \\
\hline & nad6 & 630 & ATG & TAG & 209 \\
\hline & $\operatorname{nad} 7^{a}$ & 1185 & ATG & $\mathrm{TAG}$ & 394 \\
\hline & nad9 & 573 & ATG & TAA & 190 \\
\hline \multirow{3}{*}{ Ribosomal proteins (LSU) } & $r p l 2^{a}$ & 1032 & ATG & TAA & 343 \\
\hline & rpl10 & 489 & ATG & TAA & 163 \\
\hline & rpll6 & 408 & ND & TAA & 136 \\
\hline \multirow{4}{*}{ Ribosomal proteins (SSU) } & $r p s 3^{a}$ & 1641 & ATG & TAA & 547 \\
\hline & rps4 & 969 & ATG & TAA & 322 \\
\hline & $\operatorname{rps} 7(\times 2)$ & 447 & ATG & TAA & 148 \\
\hline & rps 12 & 390 & ATG & TGA & 129 \\
\hline Succinate dehydrogenase & $s d h 4$ & 396 & ATG & TAA & 132 \\
\hline \multirow[t]{3}{*}{ Ribosomal RNAs } & $r r n 5$ & 115 & - & - & - \\
\hline & $r r n S$ & 1912 & - & - & - \\
\hline & $r r n L$ & 3321 & - & - & - \\
\hline Transfer RNAs & $\operatorname{trn} C-G C A$ & 71 & - & - & - \\
\hline
\end{tabular}




\begin{tabular}{|c|c|c|c|c|}
\hline $\operatorname{trn} C-A C A$ & 71 & - & - & - \\
\hline $\operatorname{trn} D-G U C^{b}$ & 74 & - & - & - \\
\hline $\operatorname{trn} E-U U C$ & 72 & - & - & - \\
\hline $\operatorname{trnfM}-C A U$ & 73 & - & - & - \\
\hline $\operatorname{trn} F-U G G$ & 75 & - & - & - \\
\hline $\operatorname{trn} G-G C C$ & 72 & - & - & - \\
\hline $\operatorname{trn} H-G U G^{b}$ & 73 & - & - & - \\
\hline $\operatorname{trn} H-A U G$ & 70 & - & - & - \\
\hline $\operatorname{trn} K-U U U$ & 73 & - & - & - \\
\hline $\operatorname{trn} M-C A U(\times 3)^{b}$ & 74 & - & - & - \\
\hline $\operatorname{trnN}-G U U^{b}$ & 72 & - & - & - \\
\hline $\operatorname{trn} P-G A A$ & 74 & - & - & - \\
\hline $\operatorname{trn} P-U G G$ & 75 & - & - & - \\
\hline $\operatorname{trn} Q-U U G$ & 72 & - & - & \\
\hline $\operatorname{trn} S-G C U$ & 88 & - & - & - \\
\hline $\operatorname{trn} S-U G A$ & 87 & - & - & \\
\hline $\operatorname{trn} S-G G A^{b}$ & 87 & - & - & \\
\hline $\operatorname{trn} V-G A C^{b}$ & 72 & - & - & \\
\hline $\operatorname{trn} W-C C A^{b}$ & 74 & - & - & \\
\hline $\operatorname{trn} Y-G U A^{b}$ & 83 & - & - & - \\
\hline
\end{tabular}

$2{ }^{\mathrm{a}}$ Genes containing introns.

$3 \quad{ }^{b} \mathrm{Cp}$-derived genes.

4 ND: not determined. 
Table 2 (on next page)

Comparison of genome features in six higher plant mt genomes. 
1 Table 2. Comparison of genome features in six higher plant mt genomes.

\begin{tabular}{|c|c|c|c|c|c|}
\hline \multirow[b]{2}{*}{ Plant species } & \multicolumn{4}{|c|}{ Coding regions $(\%)$} & \multirow{2}{*}{$\begin{array}{l}\text { Non-coding } \\
\text { regions }(\%)\end{array}$} \\
\hline & $\begin{array}{c}\text { Protein- } \\
\text { coding genes }\end{array}$ & $\begin{array}{l}\text { cis-spliced } \\
\text { introns }\end{array}$ & rRNAs & tRNAs & \\
\hline G. biloba & 9.95 & 11.31 & 1.44 & 0.5 & 76.8 \\
\hline Z. mays & 6.06 & 4.06 & 0.99 & 0.28 & 88.61 \\
\hline G. $\max$ & 8.48 & 8.09 & 1.31 & 0.35 & 81.77 \\
\hline G. raimondii & 5.14 & 5.28 & 1.61 & 0.28 & 87.69 \\
\hline P. populus & 3.84 & 3.33 & 0.69 & 0.21 & 91.93 \\
\hline S. suchowensis & 4.68 & 4.21 & 0.83 & 0.27 & 90.01 \\
\hline
\end{tabular}

2 


\section{Table 3 (on next page)}

Distribution of penta and hexa SSRs in the S. suchowenisis mt genome. 
1 Table 3. Distribution of penta and hexa SSRs in the S. suchowenisis mt genome.

\begin{tabular}{|c|c|c|c|c|c|}
\hline No. & Type & SSR & Start & End & Location \\
\hline 1 & penta & $($ CCTAA $) \times 3$ & 156641 & 156655 & $\mathrm{IGS}(\operatorname{trnK}-U U U, c c m F c)$ \\
\hline 2 & penta & $($ TATGG $) \times 3$ & 178046 & 178060 & $\operatorname{IGS}(c c m F c, \operatorname{cox} 1)$ \\
\hline 3 & penta & $($ GTAAA $) \times 3$ & 298400 & 298414 & $\mathrm{IGS}($ nad6, trnfM-CAU) \\
\hline 4 & penta & $($ CCTAA $) \times 3$ & 330686 & 330700 & rps3(intron) \\
\hline 5 & penta & $($ ATAAG $) \times 3$ & 400749 & 400763 & $\operatorname{IGS}(\operatorname{trn} E-U U C, \operatorname{trn} Q-U U G)$ \\
\hline 6 & penta & $(\mathrm{CTAGT}) \times 3$ & 476584 & 476598 & matR \\
\hline 7 & penta & $(\mathrm{CTCTT}) \times 3$ & 527486 & 527500 & $\operatorname{IGS}(\operatorname{trn} S-U G U, n a d 4)$ \\
\hline 8 & penta & $($ TTTTC $) \times 3$ & 528072 & 528086 & IGS(trnS-UGU, nad4) \\
\hline 9 & hexa & $($ ATAAGA $) \times 3$ & 111445 & 111462 & $\mathrm{IGS}(c c m F n, a t p 8)$ \\
\hline 10 & hexa & $($ TCCATA $) \times 3$ & 251465 & 251482 & $\operatorname{IGS}(\operatorname{trn} H, c c m B)$ \\
\hline
\end{tabular}

2 IGS: intergenic spacers. 
Table 4 (on next page)

Distribution of perfect tandem repeats in S. suchowensis mitogenome. 
1 Table 4. Distribution of perfect tandem repeats in S. suchowensis mitogenome.

\begin{tabular}{|c|c|c|c|c|c|}
\hline No. & Size(bp) & Start & Stop & Repeat sequence & Location \\
\hline \multirow[t]{2}{*}{1} & 28 & 6098 & 6153 & TATCTATTAATATCTTTT & $\operatorname{IGS}($ nad2, rpl10) \\
\hline & & & & CTTATAATGT $(\times 2)$ & \\
\hline 2 & 14 & 45814 & 45841 & AATATAGAATATAA $(\times 2)$ & $\operatorname{IGS}(\operatorname{trn} M-C A U, \operatorname{nad} 7)$ \\
\hline 3 & 13 & 94082 & 94107 & TTAGTTTATGAAT $(\times 2)$ & $\operatorname{IGS}(t r n V-G A C, c c m F n)$ \\
\hline 4 & 12 & 115524 & 115547 & GCTTTTGTCAAG $(\times 2)$ & $\operatorname{IGS}(c c m F n, a t p 8)$ \\
\hline \multirow[t]{2}{*}{5} & 14 & 124175 & 124202 & CTATAAAGATAAAG & $\operatorname{IGS}(c c m F n, a t p 8)$ \\
\hline & & & & $(\times 2)$ & \\
\hline 6 & 15 & 137256 & 137285 & СТTTTATTTTACTTA $(\times 2)$ & $\operatorname{IGS}(c c m F n, a t p 8)$ \\
\hline 7 & 13 & 144479 & 144504 & AAGAATGAATTAC $(\times 2)$ & $\operatorname{IGS}(a t p 8, \operatorname{trn} K-U U U)$ \\
\hline 8 & 13 & 166970 & 166995 & CTCGTATTCTGTA $(\times 2)$ & $\operatorname{IGS}(t r n K-U U U, c c m F c)$ \\
\hline 9 & 14 & 207285 & 207312 & ATCTATCCTACCTA $(\times 2)$ & $\operatorname{IGS}(\operatorname{trn} Y-G U A, \operatorname{trn} N-G U U)$ \\
\hline \multirow[t]{2}{*}{10} & 28 & 597277 & 597332 & TAGGACAGATGTACAA & $\operatorname{IGS}(\operatorname{trn} P-U G G, r p s 4)$ \\
\hline & & & & GGTCTTTCTTTA $(\times 2)$ & \\
\hline
\end{tabular}

2 IGS: intergenic spacers. 
Table 5 (on next page)

Distribution of repeats (>100 bp) in the S. suchowensis mt genome. 
1 Table 5. Distribution of repeats (>100 bp) in the $S$. suchowensis mt genome.

\begin{tabular}{cccccccc}
\hline \multirow{2}{*}{ No. } & \multirow{2}{*}{ Identity $(\%)$} & \multicolumn{2}{c}{ Copy-1 } & \multicolumn{2}{c}{ Copy-2 } & \multirow{2}{*}{ Size(bp) } & Type $^{\text {a }}$ \\
\cline { 3 - 6 } R1 & 99.99 & 540902 & 556493 & 644437 & 628845 & 15592 & IR \\
R2 & 99.64 & 324394 & 324672 & 420173 & 420450 & 279 & DR \\
R3 & 98.85 & 72667 & 72926 & 157110 & 156851 & 260 & IR \\
R4 & 98.5 & 454848 & 455046 & 626985 & 627184 & 199 & DR \\
R5 & 100 & 27411 & 27609 & 358568 & 358370 & 199 & IR \\
R6 & 98.34 & 218990 & 219170 & 336654 & 336834 & 181 & DR \\
R7 & 98.86 & 54691 & 54866 & 344482 & 344307 & 176 & IR \\
R8 & 99.39 & 11483 & 11646 & 195066 & 195229 & 164 & DR \\
R9 & 98.64 & 25593 & 25739 & 274499 & 274354 & 147 & IR \\
R10 & 99.22 & 384916 & 385044 & 594181 & 594309 & 129 & DR \\
R11 & 94.69 & 183152 & 183264 & 429752 & 429864 & 113 & DR \\
R12 & 100 & 602388 & 602496 & 619004 & 618896 & 109 & IR \\
R13 & 98.08 & 331484 & 331587 & 483041 & 482939 & 104 & IR \\
R14 & 84.11 & 319298 & 319401 & 378261 & 378159 & 104 & IR \\
R15 & 92.31 & 433759 & 433858 & 604908 & 604805 & 100 & IR \\
\hline
\end{tabular}

2 aDR or IR: direct or inverted repeats, respectively. 
Table 6(on next page)

Comparison of cis-/trans- splicing introns in four plant mt genomes. 
1 Table 6. Comparison of cis-/trans- splicing introns in four plant mt genomes.

\begin{tabular}{ccccc}
\hline Gene & G. biloba & T. aestivum & P. populus & S. suchowensis \\
\hline nad1 & $2 / 2$ & $1 / 3$ & $2 / 2$ & $2 / 2$ \\
nad2 & $3 / 1$ & $3 / 1$ & $3 / 1$ & $3 / 1$ \\
nad4 & $3 /-$ & $3 /-$ & $3 /-$ & $3 /-$ \\
nad5 & $2 / 2$ & $2 / 2$ & $2 / 2$ & $2 / 2$ \\
nad7 & $4 /-$ & $4 /-$ & $4 /-$ & $4 /-$ \\
atp1 & - & - & - & $-/ 1$ \\
ccmFc & $1 /-$ & $1 /-$ & $1 /-$ & $1 /-$ \\
cox2 & $2 /-$ & $1 /-$ & - & - \\
rpl2 & $1 /-$ & - & $1 /-$ & $1 /-$ \\
rps3 & $2 /-$ & $3 /-$ & $1 /-$ & $1 /-$ \\
rps10 & - & $1 /-$ & - & - \\
Total & $20 / 5$ & $19 / 6$ & $17 / 5$ & $17 / 6$ \\
\hline
\end{tabular}

2 
Table 7 (on next page)

Comparison of genome features of five plant mt genomes. 
1 Table 7. Comparison of genome features of five plant mt genomes.

\begin{tabular}{|c|c|c|c|c|c|c|}
\hline \multirow[t]{2}{*}{ Gene } & \multirow{2}{*}{$\begin{array}{c}\text { Brassicales } \\
\text { Arabidopsis } \\
\text { thaliana }\end{array}$} & \multicolumn{2}{|c|}{ Salicaceae } & \multirow{2}{*}{$\begin{array}{l}\text { Poales } \\
\text { Oryza } \\
\text { sativa }\end{array}$} & \multirow{2}{*}{$\begin{array}{c}\text { Ginkgoales } \\
\text { Ginkgo } \\
\text { biloba }\end{array}$} & \multirow{2}{*}{$\begin{array}{c}\text { Marchantiaceae } \\
\text { Marchantia } \\
\text { polymorpha }\end{array}$} \\
\hline & & $\begin{array}{l}\text { Populus } \\
\text { tremula }\end{array}$ & $\begin{array}{c}\text { Salix } \\
\text { suchowensis }\end{array}$ & & & \\
\hline Size(bp) & 366,924 & 783,442 & 644,437 & 491,515 & 346,544 & 186,609 \\
\hline $\mathrm{GC}(\%)$ & 44.77 & 44.75 & 44.98 & 43.84 & 50.36 & 42.41 \\
\hline nadl & + & + & + & + & + & + \\
\hline $\operatorname{nad} 2$ & + & + & + & + & + & + \\
\hline nad3 & + & + & + & + & + & + \\
\hline nad4 & + & + & + & + & + & + \\
\hline $\operatorname{nad} 4 L$ & + & + & + & + & + & + \\
\hline$n a d 5$ & + & + & + & + & + & + \\
\hline nad6 & + & + & + & + & + & + \\
\hline nad7 & + & + & + & + & + & pseudo \\
\hline nad9 & + & + & + & + & + & + \\
\hline$s d h 3$ & - & - & - & - & + & + \\
\hline$s d h 4$ & - & + & + & - & + & + \\
\hline$c o b$ & + & + & + & + & + & + \\
\hline $\operatorname{cox} 1$ & + & + & + & + & + & + \\
\hline $\cos 2$ & + & + & + & + & + & + \\
\hline $\cos 3$ & + & + & + & + & + & + \\
\hline atpl & + & + & + & + & + & + \\
\hline atp 4 & + & + & + & + & + & + \\
\hline atp6 & + & + & + & + & + & + \\
\hline atp 8 & + & + & + & + & + & + \\
\hline atp 9 & + & + & + & + & + & + \\
\hline $\operatorname{ccm} B$ & + & + & + & + & + & + \\
\hline $\mathrm{ccm} C$ & + & + & + & + & + & + \\
\hline$c c m F C$ & + & + & + & + & + & + \\
\hline$c c m F N$ & + & + & + & + & + & + \\
\hline matR & + & + & + & + & + & + \\
\hline$m t t B$ & + & + & + & + & + & + \\
\hline$r p l 2$ & + & + & + & + & + & + \\
\hline rpl5 & + & - & - & + & + & + \\
\hline rpl6 & - & - & - & - & - & + \\
\hline rpl10 & - & + & + & - & - & - \\
\hline rpl16 & + & pseudo & + & + & + & + \\
\hline rps 1 & - & + & - & + & + & + \\
\hline$r p s 2$ & - & - & - & + & + & + \\
\hline$r p s 3$ & + & + & + & + & + & + \\
\hline rps 4 & + & + & + & + & + & + \\
\hline
\end{tabular}




\begin{tabular}{|c|c|c|c|c|c|c|}
\hline rps 7 & + & + & + & + & + & + \\
\hline$r p s 8$ & - & - & - & - & - & + \\
\hline $\operatorname{rps} 10$ & + & - & - & - & + & + \\
\hline rps11 & - & - & - & pseudo & + & + \\
\hline rps 12 & + & + & + & + & + & + \\
\hline rps 13 & - & - & - & + & + & + \\
\hline rps14 & + & + & - & pseudo & + & + \\
\hline rps 19 & - & - & - & + & + & + \\
\hline $\operatorname{trn} A-U G C$ & - & - & - & - & - & + \\
\hline $\operatorname{trn} C-G C A$ & + & + & + & + & + & + \\
\hline $\operatorname{trn} D-G U C$ & + & + & + & + & + & + \\
\hline $\operatorname{trnE-UUC}$ & + & + & + & + & + & + \\
\hline $\operatorname{trnF-GAA}$ & - & + & + & + & + & + \\
\hline $\operatorname{trn} G-G C C$ & + & + & + & - & + & + \\
\hline $\operatorname{trn} G-U C C$ & - & - & - & - & - & + \\
\hline $\operatorname{trn} H-G U G$ & + & + & + & + & + & + \\
\hline $\operatorname{trnI}-C A U$ & + & - & - & + & - & + \\
\hline trnI-GAU & - & - & - & - & - & - \\
\hline $\operatorname{trnK} K-U U U$ & + & + & + & + & + & + \\
\hline $\operatorname{trn} L-C A A$ & - & - & - & - & - & + \\
\hline $\operatorname{trnL}-U A A$ & - & - & - & - & + & + \\
\hline $\operatorname{trn} L-U A G$ & - & - & - & - & + & + \\
\hline $\operatorname{trn} M-C A U$ & + & + & + & + & + & + \\
\hline $\operatorname{trnfM}-C A U$ & + & + & + & + & + & + \\
\hline $\operatorname{trnN}-G U U$ & + & + & + & + & - & + \\
\hline $\operatorname{trn} P-U G G$ & + & + & + & + & + & + \\
\hline $\operatorname{trn} Q-U U G$ & + & + & + & + & + & + \\
\hline $\operatorname{trn} R-A C G$ & - & - & - & - & + & + \\
\hline $\operatorname{trnR}-U C G$ & - & - & - & - & - & + \\
\hline $\operatorname{trnR}-U C U$ & - & - & - & - & + & + \\
\hline $\operatorname{trn} S-G C U$ & + & + & + & + & + & + \\
\hline $\operatorname{trnS} S-U G A$ & + & + & + & + & + & + \\
\hline $\operatorname{trn} S-G G A$ & + & + & + & + & - & - \\
\hline $\operatorname{trn} T-G G U$ & - & - & - & - & - & + \\
\hline $\operatorname{trn} T-U G U$ & - & - & - & - & - & - \\
\hline $\operatorname{trn} V-U A C$ & - & - & - & - & - & + \\
\hline $\operatorname{trn} V-G A C$ & - & - & + & - & - & - \\
\hline $\operatorname{trn} W-C C A$ & + & + & + & + & + & + \\
\hline $\operatorname{trn} Y-G U A$ & + & + & + & + & + & + \\
\hline
\end{tabular}

